\title{
DIFICULDADES DE ESCOLARIZAÇÃO NA COORDENADORIA PRISIONAL FEMININO/IAPEN/AP
}

\section{SCHOOLING DIFFICULTIES IN THE FEMALE PRISON COORDINATOR/IAPEN/AP}

\author{
Edmar dos Reis Saraiva \\ edmar@unifap.br \\ Universidade Federal Do Amapá \\ Josiane Pantoja Ferreira \\ josianepantoja@hotmail.com \\ Universidade Federal Do Amapá
}

\begin{abstract}
Resumo:
O presente estudo foi realizado na Coordenadoria da Penitenciária Feminina/IAPEN/AP ${ }^{1}$. Esse artigo tem como escopo confrontar a realidade vivenciada pelas presas no ambiente escolar prisional e o discurso oficial representado pelo conjunto de leis e regulamentos acerca da escolarização. Para dar voz as reivindicações inauditas das mulheres encarceradas, foram aplicados questionários as mulheres privadas de liberdade que estudam. Através da revisão de literatura e da aplicação dos questionários, foi possível constatar alguns dos empecilhos no processo de escolarização das mulheres presas. Para finalizar, ressalta-se a importância de compreender o ambiente escolar da prisão, como um ambiente, propicio a potencializar ações de reintegração social, porém é fundamental que os direitos sejam efetivados, ou seja, sair da retórica para ação.
\end{abstract}

Palavras-chave: Penitenciária, Educação, Mulher Privada de Liberdade.

\begin{abstract}
:
The present study was conducted in the coordination of the Women's penitentiary/IAPEN/AP. This article is scoped to confront the reality experienced by prey in the prison school environment and the official discourse represented by the set of laws and regulations about schooling. To give voice to the inaudited demands of imprisoned women, questionnaires were applied to women deprived of freedom who study. Through the literature review and the application of the questionnaires, it was possible to observe some of the obstacles in the schooling process of the women arrested. Finally, we emphasize the importance of understanding the school environment of prison, as an environment, to potentialize actions of social reintegration, but it is fundamental that the rights are effective, that is, to leave the rhetoric for action.
\end{abstract}

Key words: Penitentiary, education, Woman without liberty.

\footnotetext{
${ }^{1}$ IAPEN - AP: Instituto de Administração Penitenciária do Amapá.
} 
INTRODUÇÃO

O presente artigo tem como escopo evidenciar a finalidade da pena, o arcabouço normativo que assegura o direito a educação escolar as pessoas em privação de liberdade, bem como mostrar as dificuldades que as internas enfrentam no processo de escolarização.

A educação escolar, ofertada no ambiente carcerário é fundamental para que as internas possam vislumbrar uma vida fora do mundo da criminalidade, pois às vezes as mulheres encarceradas têm seu primeiro contato com a escola quando estão cumprindo pena de restrição de liberdade. Portanto, o presente estudo foi realizado por meio de revisão bibliográfica e pesquisa de campo, tendo como instrumento de coleta de dados o questionário, para que fosse possível desvendar um pouco das nuances da realidade da escola prisional.

\section{A EDUCAÇÃO NO SISTEMA PRISIONAL: GARANTIA LEGAL}

A finalidade da pena segundo as teorias absolutas (retribucionistas ou de retribuição) é o castigo do prisioneiro, como forma de pagamento pelo mal causado a sociedade. Para as teorias relativas (utilitárias ou utilitaristas), a pena tem o objetivo de prevenção de futuros delitos, dividindo-se em prevenção geral (que diz respeito a todos da sociedade) ou especial (com relação ao sentenciado). Já para as teorias mistas (ecléticas ou intermediarias), a pena é tanto uma retribuição ao condenado pela realização de um crime, como uma forma de prevenir a realização de novos delitos, sendo assim uma mistura de educação e correção, (MIRABETE, 2007).

Com base na teoria mista, começam a surgir sistemas prisionais fundados no ideário de que a execução penal deve possibilitar a transformação do criminoso, por meio da educação, tentando influenciar suas atitudes e o seu comportamento social. De acordo, com as regras mínimas para tratamento de prisioneiro no item 65 ,

O tratamento dos condenados a uma punição ou medida privativa de liberdade deve ter por objetivo, enquanto a duração da pena o permitir, inspirar-lhes a vontade de viver conforme a lei, manter-se com o produto do seu trabalho e criar neles a aptidão para fazêlo. Tal tratamento estará direcionado a fomentar-lhes o respeito por si mesmos e a desenvolver seu senso de responsabilidade. 
Nesse sentido, a finalidade da pena será além da punição proporcionar a interna um tratamento, onde a mulher encarcerada tenha no futuro uma vida fundada na responsabilidade social, sem ações criminosas, para isso, é fundamental respeitar suas particularidades, com a retirada de obstáculos colocados pela privação de liberdade.

As regras mínimas para o tratamento de prisioneiros, estabelece no item 77, atinente a educação que:

\footnotetext{
Serão tomadas medidas para melhorar a educação de todos os presos em condições de aproveitá-la, incluindo instrução religiosa nos países em que isso for possível. A educação de analfabetos e presos jovens será obrigatória, prestando-lhe a administração especial atenção.

Tanto quanto possível, a educação dos presos estará integrada ao sistema educacional do país, para que depois da sua libertação possam continuar, sem dificuldades, a sua educação.
}

Com o advento da Lei 7.210/84, Lei de Execuções Penais (LEP), institui-se expressamente em texto legal a finalidade reeducativa da pena, e a sua efetivação através dos direitos, assistências e garantias à pessoa presa, dentre as quais está à assistência à educação.

Tal direito veio a ser reforçado no texto constitucional de 1988, que menciona em seu bojo, o direito a educação como direito social e dever do Estado, o artigo 205 da CF, estabelece que "A educação, direito de todos e dever do Estado da família, será provida e incentivada com a colaboração da sociedade, visando ao pleno desenvolvimento da pessoa, seu preparo para o exercício da cidadania (...)". Logo, as pessoas que cumprem pena restritiva de liberdade, devem ter seu direito de acesso e permanência a educação respeitada.

Acrescenta-se, que é dever do Município e do Estado com o subsídio da União, promover a educação das pessoas privadas de liberdade, conforme referendado na LEP, art. 18-A, $\S 1$ 우: “O ensino ministrado às internas integrar-se-á ao sistema estadual e municipal de ensino e será mantido, administrativa e financeiramente, com o apoio da União".

Para atender ao princípio Constitucional da Universalização do Ensino médio, regular ou supletivo, com formação geral ou educação profissional, foi incluído recentemente no ano de 2015 na LEP, o artigo 18-A. Percebe-se, o intuito do legislador de deixar claro que o direito a educação não se restringe ao indivíduo livre, mas estende-se àquele que não desfruta de sua liberdade. 
Há determinação legal, prevista no art.19 Parágrafo único, para que "A mulher condenada terá ensino profissional adequado à sua condição". A mulher receberá assim uma formação profissional de caráter cultural. Mirabete (2007, p. 76), frente à temática elucida a habilitação profissional como um requisito da função utilitarista da prisão, “(...) pois, facilita a reinserção do condenado no convívio familiar, comunitário e social, a fim de que não volte a delinquir".

A educação, segundo o artigo 26, da Declaração Universal dos direitos humanos é um direito de todos, incluindo, portanto, os encarcerados, pois:

1. Todo ser humano tem direito à instrução. A instrução será gratuita, pelo menos nos graus elementares e fundamentais. A instrução elementar será obrigatória. A instrução técnico-profissional será acessível a todos, bem como a instrução superior, esta baseada no mérito.

2. A instrução será orientada no sentido do pleno desenvolvimento da personalidade humana e do fortalecimento do respeito pelos direitos do ser humano e pelas liberdades fundamentais. A instrução promoverá a compreensão, a tolerância e a amizade entre todas as nações e grupos raciais ou religiosos e coadjuvará as atividades das Nações Unidas em prol da manutenção da paz.

A educação nesse contexto contribui para a construção de uma sociedade mais pacifica. A pessoa presa que participa do processo educacional no sistema penal é assegurado o instituto da remição, como mencionado na LEP Art. 126, "O condenado que cumpre a pena em regime fechado ou semiaberto poderá remir, por trabalho ou por estudo, parte do tempo de execução da pena", esse artigo 126, menciona somente que os presos do regime fechado ou semiaberto poderão usufruir de tal instituto, ocorre que $\circ \S 6^{\circ}$ do referido artigo relata que 0 condenado que cumpre pena em regime aberto também faz jus à remição da pena.

A luz do art. $126, \S 1^{\circ}, \mathrm{I}$, a contagem de tempo para a remição é realizada da seguinte forma "1 (um) dia de pena a cada 12 (doze) horas de frequência escolar - atividade de ensino fundamental, médio, inclusive profissionalizante, ou superior, ou ainda de requalificação profissional - divididas, no mínimo, em 3 (três) dias".

As atividades educacionais podem ser realizadas de maneira presencial ou por metodologia de ensino a distância. O preso impossibilitado, por acidente, de prosseguir em seus estudos continuará a beneficiar-se com a remição. A LEP em seu art. 126 , §5으 cita que: “O tempo a remir em função das horas de estudo será acrescido de 1/3 (um terço) no caso de conclusão do ensino fundamental, médio ou superior durante o cumprimento da pena (...)". 
A Resolução № 03, de 11 de março de 2009, do Conselho Nacional de Política Criminal (CNPCP), mostra uma preocupação em propiciar a educação não só no ambiente intramuros, mas também extramuros, quando a pessoa presa sai da prisão e recebe a liberdade. Pois, a luz do Art. 70 - Devem ser elaboradas e priorizadas estratégias que possibilitem a continuidade de estudos para os egressos, articulando-as com entidades que atuam no apoio dos mesmos (...)".

A resolução supracitada em seu art. 10 Parágrafo único, recomenda que: “(...) a cada unidade da federação, que as ações de educação formal sigam um calendário comum aos estabelecimentos penais onde houver oferta", a fim de, possibilitar a continuidade do processo ensino-aprendizagem.

Desta forma, o ensino recebido nos estabelecimentos prisionais tem a mesma validade que a prestada pela rede escolar pública ou particular, proporcionando dessa maneira que a mulher em privação de liberdade ao sair da penitenciária, possa prosseguir seus estudos.

\title{
ELEMENTOS QUE EVIDENCIAM DIFICULDADES DE ESCOLARIZAÇÃO NA COORDENADORIA PRISIONAL FEMININO/IAPEN/AP
}

A educação escolar no ambiente prisional tem importância fundamental no processo de escolarização, uma vez que, segundo Serrão; Baleeiro, (1999 apud Luz; Pereira, 2014, p.251 e 252),

\begin{abstract}
Abre a possibilidade de se transformar o homem anônimo, sem rosto, naquele que sabe, que pode escolher, que é sujeito participante de sua reflexão, da reflexão do mundo e de sua própria história, assumindo a sua responsabilidade de seus atos e das mudanças que fizer acontecer. Esta chave nos permite modificar a realidade, alterando o seu rumo, provocando as rupturas necessárias e aglutinando as forças que garantem a sustentação de espaços onde o novo seja buscado, construído, refletido.
\end{abstract}

A educação no sistema prisional possibilita a mudança de pensamentos e atitudes, contribuindo com a mudança de comportamento do sujeito, para essa transformação acontecer e necessário que se removam algumas barreiras como à falta de vagas nas escolas da prisão, pois no ano de 2015 , somente $25,3 \%$ da população carcerária feminina estava atividades de escolarização. (DEPEN/MJ, 2015). 
Nesse sentido, é importante que além da garantia de acesso a escola, seja garantida a permanência, para isso, recursos humanos, estrutura física da escola e materiais escolares, são fundamentais. No questionário aplicado as reeducandas indagou-se: Qual sua maior dificuldade para continuar estudando na escola da penitenciária?

As respostas foram as seguintes:

Aluna 20: É porque a escola não tem: caderno, lápis, caneta, borracha e apontador.

Aluna 18: É porque a escola não tem material escolar.

Aluna 7: Falta de material, pois nem todas as internas têm condições ou familiar para comprar o material da escola.

As internas sinalizam a ausência de material escolar, porém, de acordo com a Resolução № 02 de 2010 da CEB, em seu artigo 8, o Governo é o responsável pelo fornecimento de material didático e escolar para as pessoas que frequentam a escola.

Tiveram internas que relataram como empecilho para sua jornada escolar problemas oftalmológicos, vejamos:

Aluna 21: Queria muito poder continuar a estudar, mas estou com problema na minha visão, mas sou agradecida por esses cinco anos que estudei, deu para aprender muito com os ensinamentos dos professores que passaram por aqui.

Aluna 19: Minha deficiência visual.

Percebemos com esses relatos, a ausência ou insuficiência do atendimento médico oftalmológico refletindo diretamente no atendimento educacional, a assistência à saúde é um direito social garantido pela nossa CF/1988 bem como pela LEP, a negativa a tal direito influencia nas condições de ensino-aprendizagem e consequentemente no aproveitamento escolar.

Outras reeducandas citam as revistas realizadas como barreira para prosseguir os estudos, observemos:

Aluna 16: Revistas.

Aluna 22: Excesso de revista que temos que passar para ir à escola.

Aluna 2: As revistas que somos submetidas, todos os dias, quando voltamos da escola.

Nesse enfoque, é necessário trabalhar com as mulheres encarceradas a importância dessas revistas, pois, no ambiente prisional é fundamental esse cuidado, pela segurança de todos. 
Os servidores penitenciários ao realizarem esse procedimento estão cumprindo com seu dever funcional, para amenizar tal situação o ideal seria que tivesse o scanner corporal.

Em seguida indagamos: Em sua opinião o que deve melhorar na escola? As mulheres privadas de liberdade responderam:

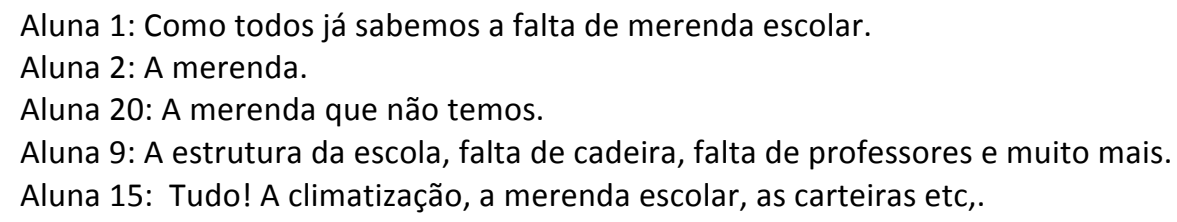

A alimentação escolar, a luz do art. 208, inciso VII da CF é um dever do Estado com a Educação que será garantida “(...) ao educando, em todas as etapas da educação básica, por meio de programas suplementares de (...) alimentação e assistência à saúde". O lanche escolar é um atrativo para que as internas frequentem com assiduidade a escola, pois as reclusas buscam por meio da escola uma alimentação melhor do que a recebida dentro das celas. Vale ressaltar, que na coordenadoria prisional feminino/IAPEN, as internas recebem três refeições diárias, café da manhã, o almoço e o jantar.

As reeducandas pontuam que também deve melhorar na escola a situação da carência de professores, observemos: A Aluna 10 relata que:

Quando começam as aulas faltam professores e quando providenciam já está no meio do ano.

Ainda com relação aos professores as reeducandas falam:

Aluna 13: A falta de interesse de alguns professores em questão a gente.

Aluna 6: A falta dos professores e muito mais

Aluna 19: Tudo, principalmente os professores.

Nesse diapasão, as reeducandas apontam a falta de materiais escolares e a falta de infraestruturas:

Aluna 6: A estrutura, e mais material escolar, as cadeiras que estão todas quebradas, a central que não funciona, os materiais para dar uma boa aula e muitas outras coisas Aluna 11: A iluminação e as centrais, pois estão em estados precários e a merenda que já não tem mais. 
De acordo com Luz; Pereira, 2014, p.254 “As questões arquitetônicas das unidades prisionais dificilmente contemplam em seus projetos espaços específicos para escolarização".

A falta de espaço físico adequado, fica evidente no desejo de algumas alunas que almejam que:

"Em algumas matérias tenham aulas práticas, como na matéria de educação física". Aluna 22.

Essa questão de aula prática demanda um espaço apropriado para tal atividade acontecer, o direito a um espaço adequado já é garantido na Resolução № 02 de 2010 da CEB, no art. 70, entretanto, ainda não é concretizado, o referido artigo prevê que:

As autoridades responsáveis pela política de execução penal nos Estados e Distrito Federal deverão, (...), propiciar espaços físicos adequados às atividades educacionais, esportivas, culturais, de formação profissional e de lazer, integrando-as às rotinas dos estabelecimentos penais.

Nessa acepção, as reeducandas apontam:

Aluna 7: “A climatização das salas, que não funcionam, (...), equipamentos e materiais eletrônicos para nossos professores passarem uma boa aula (data-show, caixa amplificada, microfone e etc.)".

A Resolução № 02 de 2010 da CEB, em seu artigo 5o já estabelece que “Os Estados, (...) deverão incentivar a promoção de novas estratégias pedagógicas, produção de materiais didáticos e a implementação de novas metodologias e tecnologias educacionais".

Porém, de acordo com os relatos das reeducandas é uma norma que até o presente momento não vem sendo efetivada, outra interna (aluna 14) corrobora relatando a importância de um laboratório de informática dizendo que:

As vezes precisamos e não temos, um espaço e condições, tipo queremos fazer uma pesquisa e não encontramos o conteúdo na biblioteca e acabamos ficando sem fazer, uma sala de informática seria muito bom. 


\section{DIFICULDADES DE ESCOLARIZAÇÃO NA COORDENADORIA PRISIONAL FEMININO/IAPEN/AP}

Nesse relato, verifica-se o anseio por espaços de escolarização adequados, observemos o que reza a Resolução no-- 03, de 2009, Art. 5o: “As autoridades responsáveis pelos estabelecimentos penais devem propiciar espaços físicos adequados às atividades educacionais (...)".

Diante das normativas e dos relatos colhidos com as mulheres encarceradas, visualizamos um ambiente prisional com algumas precariedades, onde falta, biblioteca, laboratórios, material escolar, recursos humanos e outros. É nesse cenário cercado de mazelas sociais, que o professor exerce seu oficio. Nos dizeres de Luz; Pereira, 2014, p.123

(...) torna-se fundamental a formação dos/as educadores/as no sentido de refletir sobre a prática docente no interior da prisão, além de ser imprescindível a compreensão do espaço onde a escola está inserida, visando estabelecer uma estratégia educativa capaz de abranger a instituição e seus sujeitos.

Portanto, o professor é um dos atores que tem a capacidade de por meio de seu ensinamento contribuir com o processo de ressocialização, sensibilizando as reeducandas, e buscando sua humanização, com o fito de semear a força da mudança e da libertação.

\section{CONSIDERAÇÕES FINAIS}

Evidencia-se no presente artigo que existem políticas públicas voltadas para as pessoas encarceradas, contudo sua implementação está longe de ser efetivada nos moldes estabelecidos. Como demonstrado, às vezes, essas políticas não são aplicadas ou são aplicadas com vícios, logo, os gestores se preocupam em garantir somente os requisitos formais estabelecidos na legislação.

Nesse sentido, a contribuição da educação com a ressocialização fica comprometida, uma vez, que os empecilhos são inúmeros, a estrutura física da escola não conta com: sala de professores, laboratório de informática, laboratório de ciências, sala de leitura, quadra de esporte, sala de atendimento educacional especializado adequada e a biblioteca funciona no improviso junto com a sala da coordenação pedagógica.

Concluiu-se que as barreiras para uma educação de qualidade são gigantescas e que é necessária uma maior fiscalização na oferta da educação escolar prisional, pois como foi mostrado há um imenso abismo entre o mundo nas normativas legais e a realidade vivenciada pelas 
mulheres encarceradas, comprometendo assim a qualidade do ensino, e restringindo a contribuição da educação escolar para o processo de ressocialização.

\section{REFERÊNCIAS BIBLIOGRÁFICAS}

BRASIL. Constituição da República Federativa do Brasil. 1988. Brasília: Senado Federal, 2001. 407p.

. Lei de Execução Penal. Lei № 7.210 de 11 de julho de 1984. Institui a Lei de Execução Penal. Disponível em: < http://www.planalto.gov.br/ccivil_03/leis/l7210compilado.htm >. Acesso em: 01 mar. 2018.

. Ministério da Justiça. Departamento Penitenciário Nacional. Sistema Integrado de Informações Penitenciárias. Disponível em:<http:www.mj.gov.br.> Acesso em 26 jul. 2017.

. Resolução № 03, de 11 de março de 2009, do Conselho Nacional de Política Criminal CNPCP. Estabelece as Diretrizes Nacionais para a oferta de Educação nos Estabelecimentos Penais. 2009. Disponível em: http://www.justica.gov.br/seus-direitos/politica-penal/cnpcp1/resolucoes/resolucoes-arquivos-pdf-de-1980-a-2015/ resolucao-n-o-3-de-11-de-marco-de2009.pdf. Acesso em: 01 mar. 2018.

. Resolução CNE/CEB № 02 de 19 de Maio de 2010. Dispõe sobre as Diretrizes Nacionais para a oferta de educação para jovens e adultos em situação de privação de liberdade nos estabelecimentos $\quad$ penais. $2010 . \quad$ Disponível em:<http://portal.mec.gov.br/index.php?option=com_content\&id=14906\& Itemid=866>. Acesso em: 21 abr. 2017.

LUZ, Araci Asinelli; PEREIRA, Ires Aparecida Falcade. A escola como espaço de (RE)socialização e (RE)inserção social para mulheres em privação de liberdade. In: LUZ, Araci Asinelli; PEREIRA, Ires Aparecida Falcade (orgs). O espaço prisional: estudos, pesquisas e reflexões de práticas educativas. 1ㅁ Ed. Curitiba: Appris, 2014.

MIRABETE, Julio Fabbrini. Execução Penal. 11ạ ed. São Paulo: Atlas, 2007.

ONU. Regras Mínimas para o Tratamento de Prisioneiros. 1955. Disponível em: http://www.dhnet.org.br/direitos/sip/onu/fpena/lex52.htm. Acesso em 07 out. 2017.

Declaração Universal dos Direitos Humanos. 1948. Disponível em: http://www.ohchr.org/EN/UDHR/Documents/UDHR_Translations/por.pdf. Acesso em 01 mar. 2018.

Artigo submetido em 18/04/2019, e aceito em 14/08/2019. 